\title{
Design of normally-off GaN-based T-gate with Drain-Field-Plate (TGDFP) HEMT for power and RF applications
}

\author{
Mansoor Ali Khan and Hyun Chang Park ${ }^{\mathrm{a})}$ \\ Division of Electronics and Electrical Engineering, Dongguk University-Seoul, \\ Seoul, 100-715, Korea \\ a)hcpark@dongguk.edu
}

Abstract: In this paper, an effective T-gate with Drain-Field-Plate (TGDFP) technology is used in GaN-based HEMT for high breakdown voltage of $500 \mathrm{~V}$ and drain current of $540 \mathrm{~mA} / \mathrm{mm}$. Silvaco TCAD simulation showed that normally-off TGDFP HEMT with recessed gate length of $0.5 \mu \mathrm{m}$ exhibited high threshold voltage up to $+1 \mathrm{~V}$ and transconductance of $140 \mathrm{mS} / \mathrm{mm}$ along with frequency operation in Sband $(\sim 3 \mathrm{GHz})$. The proposed lateral TGDFP HEMT provides desirable features for both Power and RF applications.

Keywords: HEMT, GaN, field-plate (FP), lateral, TGDFP, power, $\mathrm{RF}$

Classification: Electron devices, circuits, and systems

\section{References}

[1] U. K. Mishra, Y.-F. Wu, B. P. Keller, S. Keller and S. P. Denbaars: IEEE Trans. Microw. Theory Tech. 46 (1998) 756.

[2] U. K. Mishra, P. Parikh and Y.-F. Wu: IEEE Proc. 90 [6] (2002) 1002.

[3] E. T. Yu, X. Z. Dang, P. M. Asbeck, S. S. Lau and G. J. Sullivan: American J. Vac. Sci. Technol. B17 [4] (1999) 1742.

[4] R. Quay: Gallium Nitride Electronics (Springer Series in Material Science, Germany, 2008) 96.

[5] A. N. Alderman: Power Electronics Technology (2010) http://www.powerelectronics.com.

[6] R. Vetury, N.-Q. Zhang, S. Keller and U. K. Mishra: IEEE Electron Device Lett. 48 (2001) 560.

[7] T. Kachi: IEEE Comp. Semi. Int. Circ. Sympo. 07 (2007) 1.

[8] M. A. Khan, J.-W. Heo, Y.-J. Kim, H.-C. Park, H.-M. Park, H.-S. Kim and J.-K. Mun: J. Korean Phys. Soc. 62 (2013) 787.

[9] TCAD ATLAS release 5.18.3.R, Semiconductor Device Modeling System: Silvaco Inc., California (2013).

[10] D. J. Denninghoff, S. Dasgupta, J. Lu, S. Keller and U. K. Mishra: IEEE Electron Device Lett. 33 (2012) 785.

[11] W. Saito, Y. Takada, M. Kuraguchi, K. Tsuda and I. Omura: IEEE Trans. Electron Devices 53 (2006) 356. 
[12] N. Tipirneni, A. Koudymov, V. Adivarahan, J. Yang, G. Simin and M. Asif Khan: IEEE Electron Device Lett. 27 (2006) 164.

[13] S. Russo and A. Di Carlo: IEEE Trans. Electron Devices 54 (2007) 1071.

[14] N.-Q. Zhang, S. Keller, G. Parish, S. Heikman, S. P. DenBaars and U. K. Mishra: IEEE Electron Device Lett. 21 (2000) 421.

[15] Y. Ando, Y. Okamoto, H. Miyamoto, T. Nakayama, T. Inoue and M. Kuzuhara: IEEE Electron Device Lett. 24 (2003) 289.

[16] Y.-F. Wu, A. Saxler, M. Moore, R. P. Smith, S. T. Sheppard, P. M. Chavarkar, T. Wisleder, U. K. Mishra and P. Parikh: IEEE Electron Device Lett. 25 (2004) 117.

[17] S. Karmalkar, J. Deng, M. S. Shur and R. Gaska: IEEE Electron Device Lett. 22 (2001) 373.

[18] W. Saito, M. Kuraguchi, Y. Takada, K. Tsuda, I. Omura and T. Ogura: IEEE Electron Device Lett. 52 (2005) 106.

\section{Introduction}

GaN as III-Nitride semiconductor possesses superior figures of merits as compared to GaAs, $\mathrm{SiC}$, or $\mathrm{Si}$; such as wide bandgap $(3.4 \mathrm{eV})$, high saturation velocity $\left(2.5 \times 10^{7} \mathrm{~cm} / \mathrm{s}\right)$, high sheet carrier density $\left(1 \times 10^{13} / \mathrm{cm}^{2}\right)$ and high breakdown electric field $(3.3 \mathrm{MV} / \mathrm{cm})$ which make it feasible for high-power and high-frequency transistors $[1,2]$. Also, its chemical (piezoelectric) and mechanically stable (rugged) properties make it an excellent candidate for timing and sensing applications [3, 4]. As a result, GaN HEMTs are replacing GaAs and Si-based IGBTs in power electronics applications, like hybrid vehicles (HVs), electric vehicles (EVs), power line conditioner and $\mathrm{AC} / \mathrm{DC}$ servo motor drives [3]. During DC-to-AC conversion process, replacing Si with GaN helps to minimize the switching and conduction losses by factor of two to six times respectively $[4,5]$. Also, in terms of power performance, $\mathrm{GaN}$ is two times better than $\mathrm{SiC}$ along with its compatibility with low cost and large foundation Si substrate [4]. On the performance-based criteria, two types of GaN HEMTs are currently well known. One is vertical HEMT with the characteristics of high breakdown voltage, high current density and high on-resistance, while second category is lateral HEMT for low power devices but combined with high frequencies and low on-resistance merits. Although vertical devices have advantages like small size and less current collapse (surface states) operation [6], the high cost of free standing GaN substrate is the major hurdle for the vertical devices [7]. Further, vertical structure lacks in traits like high frequency operation and low-on resistance that are strongly required for the future power electronic devices $[4,7]$.

In this paper, a lateral GaN-based HEMT incorporating T-gate with Drain-Field-Plate (TGDFP) has been proposed for power electronic devices by integrating all the key features like normally-off (E-HEMT) operation, high breakdown voltage, and high drain current. This device can work in gigahertz frequencies, a highly demanded frequency band of wireless communication. 


\section{TGDFP design and DC characteristics}

Fig. 1 shows the cross-sectional schematic of the proposed TGDFP HEMT based on the reference model in [8]. DC and RF results are obtained and analyzed by two-dimensional numerical device simulator Silvaco-TCAD [9]. The device has compact source-drain spacing of $6.6 \mu \mathrm{m}$, and gate length $\left(\mathrm{L}_{\mathrm{G}}\right)$ of $0.5 \mu \mathrm{m}$. The T-gate structure is selected over the gamma $(\Gamma)$-gate because of its both arms (field-plates) minimizing the electric field and current dispersion at the source-side and drain-side edges of the gate [8]. Also, T-gate is better for its low gate-resistance in high-frequency applications $[4,10]$.

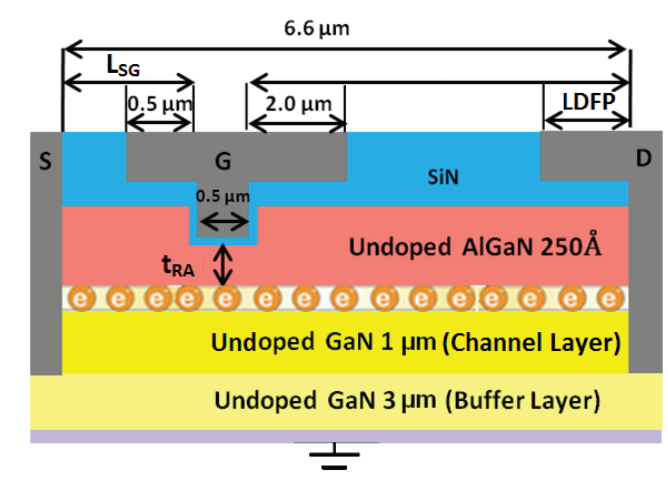

Fig. 1. Cross-sectional schematic of TGDFP GaN HEMT.

In this design, three vital factors have been considered to attain high performance both in power and operation frequency. The first factor is the normally-off (E-HEMT) operation with a positive DC supply, which is required for switching power devices [11]. This is achieved by thinning the AlGaN layer only under the gate electrode to form a recess-gate structure which decreases the Schottky barrier thickness and carrier density, and hence results in shifting the threshold voltage $\left(\mathrm{V}_{\mathrm{TH}}\right)$ towards the positive side [8]. For $\mathrm{V}_{\mathrm{TH}}$ calculation, source-to-gate distance $\left(\mathrm{L}_{\mathrm{SG}}\right)$ of $1.8 \mu \mathrm{m}$, gate-to-drain distance $\left(\mathrm{L}_{\mathrm{GD}}\right)$ of $4.3 \mu \mathrm{m}$ and no drain-field-plate $(\mathrm{LDFP}=0.0 \mu \mathrm{m})$ are used. We find that with the remaining AlGaN layer thickness ( $\left.t_{R A}\right)$ of $5 \mathrm{~nm}$, the 2DEG channel gets fully established and the device starts conducting when $\mathrm{V}_{\mathrm{GS}} \geq 1 \mathrm{~V}$. Thus $\mathrm{V}_{\mathrm{TH}}$ is defined to be $1 \mathrm{~V}$ at $\mathrm{V}_{\mathrm{DS}}=12 \mathrm{~V}$ as evident in Fig. 2.

The second factor included in the TGDFP design is the gate-shifting towards source-side in order to minimize $\mathrm{L}_{\mathrm{SG}}$. While keeping the parameters of $\mathrm{t}_{\mathrm{RA}}=5 \mathrm{~nm}$ and $\mathrm{LDFP}=0.0 \mu \mathrm{m}$, when $\mathrm{L}_{\mathrm{SG}}$ is reduced from $1.8 \mu \mathrm{m}$ to $0.8 \mu \mathrm{m}$, considering the practical limitation due to fabrication margins, device I-V characteristics generally improved as shown in Fig. 3 and Fig. 4. Fig. 3 (a) shows that at $V_{D S}$ of $12 \mathrm{~V}$, there is no change in $V_{T H}$ on decreasing $\mathrm{L}_{\mathrm{SG}}$, because Schottky barrier thickness that affects the 2DEG channel has not changed. However, the transconductance $\left(G_{m}\right)$ has increased from $110 \mathrm{mS} / \mathrm{mm}$ to $140 \mathrm{mS} / \mathrm{mm}$ as depicted in Fig. 3 (b). The reason is that shifting the recessed gate towards source-electrode minimizes the space 

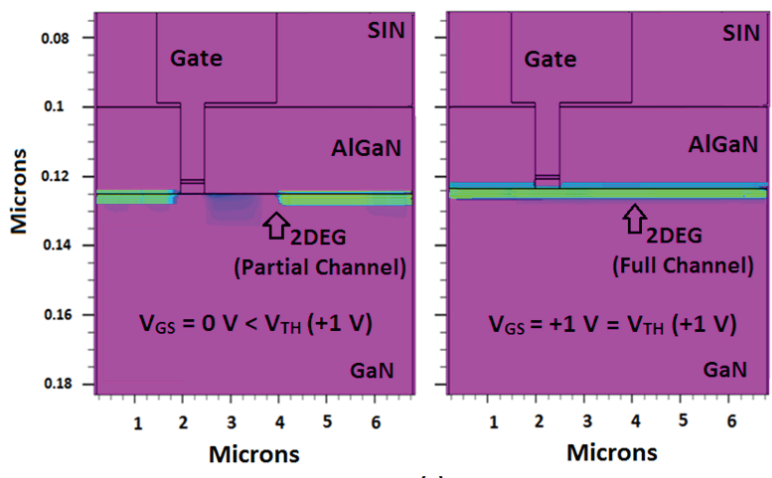

(a)

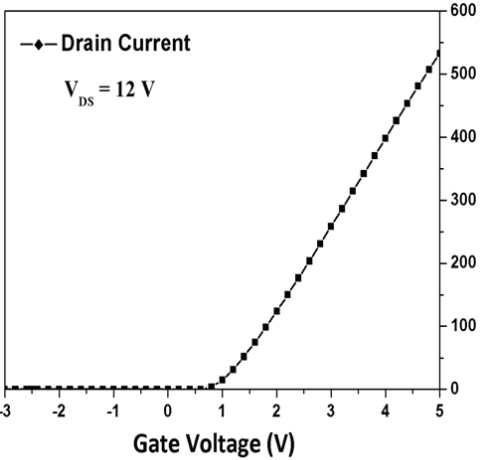

(b)

Fig. 2. (a) 2DEG channel and (b) Threshold voltage for the proposed GaN HEMT.

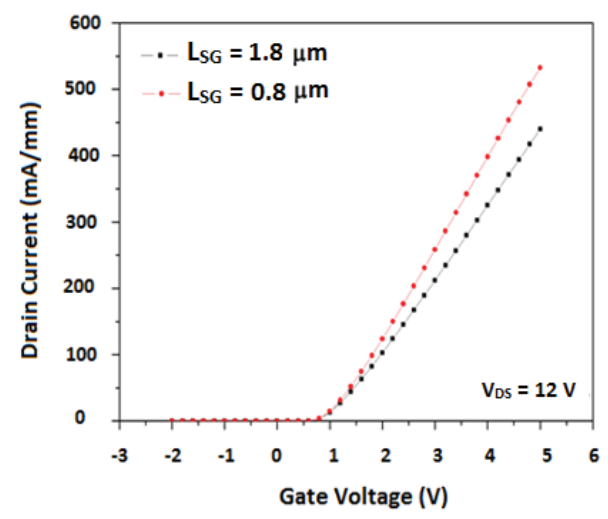

(a)

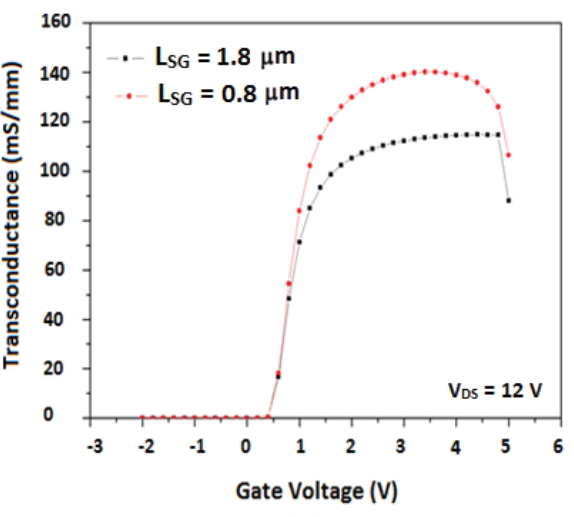

(b)

Fig. 3. Gate-shifting impact on (a) $\mathrm{V}_{\mathrm{TH}}$, (b) $\mathrm{G}_{\mathrm{m}}$.

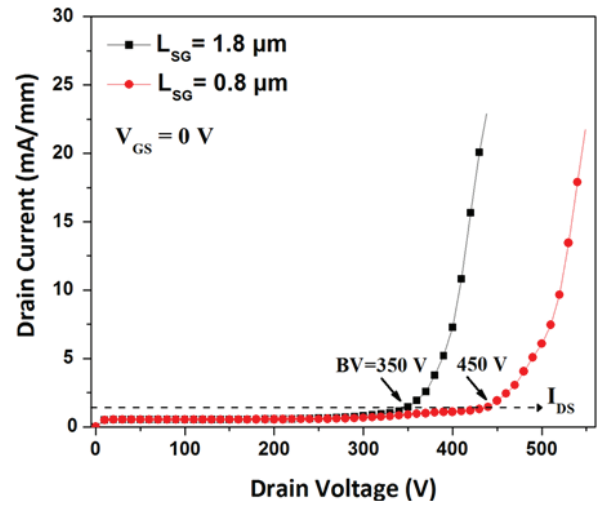

(a)

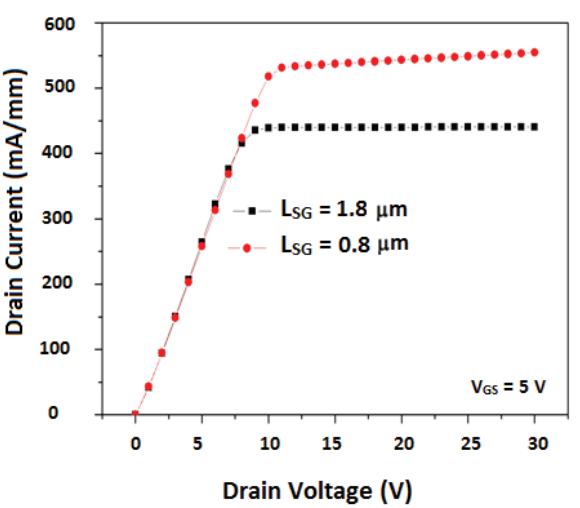

(b)

Fig. 4. Gate-shifting impact on (a) $\mathrm{V}_{\mathrm{BR}}$ and (b) $\mathrm{I}_{\mathrm{DS}}$.

charge region (resistive element) $[4,8]$, and hence decreases the source-access resistance.

Fig. 4 (a) shows that the off-state $\left(\mathrm{V}_{\mathrm{GS}}=0 \mathrm{~V}\right)$ breakdown voltage $\mathrm{V}_{\mathrm{BR}}$ defined at a low leakage current of $1 \mathrm{~mA} / \mathrm{mm}$ has been increased from 350 to $450 \mathrm{~V}$. In fact, shifting the T-gate towards the source-electrode increases the critical parameter of $\mathrm{L}_{\mathrm{GD}}$ from $4.3 \mu \mathrm{m}$ to $5.3 \mu \mathrm{m}$, a region that accommodates most of the applied voltage and thus enhances the $V_{B R}$ without varying the device length [12]. Also, Fig. 4 (b) shows that at an open channel condition 
$\left(\mathrm{V}_{\mathrm{GS}}=5 \mathrm{~V}\right)$, the drain current $\left(\mathrm{I}_{\mathrm{DS}}\right)$ has been increased from $440 \mathrm{~mA} / \mathrm{mm}$ to $540 \mathrm{~mA} / \mathrm{mm}$. This $\mathrm{I}_{\mathrm{DS}}$ enhancement is related to two possible reasons. First is the decrease in the source-access resistance. Second is the unique velocityfield behavior of $\mathrm{GaN}$ in the source-gate region $(\mathrm{S}-\mathrm{G})$ [13]. $\mathrm{L}_{\mathrm{SG}}$ reduction increases the $\mathrm{S}-\mathrm{G}$ electric field, causing an increase of average electron velocity component along the channel, and consequently, an increase of $\mathrm{I}_{\mathrm{DS}}$ in the non-saturation regime. Hence, although $\mathrm{I}_{\mathrm{DS}}$ is almost independent of the $\mathrm{L}_{\mathrm{GD}}$ variation [14], it can be distinctly improved by the $\mathrm{L}_{\mathrm{SG}}$ scaling in $\mathrm{GaN}$ HEMTs.

Lastly, the third critical factor is the uniform distribution of electric field from source to drain electrodes [15, 16]. Additional metal as a field-plate (FP) on the gate and drain-electrodes can uniformly terminate those electric field resulting in high $\mathrm{V}_{\mathrm{BR}}[4,17,18]$. The recess $\mathrm{T}$-gate with its both side arms (FP) covers the electric field beneath the gate-corners and distributes them to the drain-side electrode. However, this causes an increase of electric field at a local edge of the drain-electrode as verified from Fig. 5 (a). Here, $\mathrm{t}_{\mathrm{RA}}$ of $5 \mathrm{~nm}$ and gate-shifted parameters $\left(\mathrm{L}_{\mathrm{SG}}=0.8 \mu \mathrm{m}\right.$ and $\left.\mathrm{L}_{\mathrm{GD}}=5.3 \mu \mathrm{m}\right)$ are used at $\mathrm{V}_{\mathrm{GS}}=0 \mathrm{~V}$ and $\mathrm{V}_{\mathrm{DS}}=450 \mathrm{~V}$. This peak electric field must be compensated by another FP aligned to the drain-electrode (DFP) to maintain the electric field below the critical value $\left(\mathrm{E}_{\mathrm{C}}=3 \sim 3.3 \mathrm{MV} / \mathrm{cm}\right.$ for $\left.\mathrm{GaN}\right)$ in order to improve the $\mathrm{V}_{\mathrm{BR}}$.

Fig. 5 (b) compares off-state breakdown voltages of T-gate devices without DFP (TG) and with DFP (TGDFP). For both devices, $t_{\mathrm{RA}}=5 \mathrm{~nm}$, $\mathrm{L}_{\mathrm{SG}}=0.8 \mu \mathrm{m}, \mathrm{L}_{\mathrm{GD}}=5.3 \mu \mathrm{m}$ and $\mathrm{V}_{\mathrm{GS}}=0 \mathrm{~V}$ were used. It is shown that TG device has off-state $\mathrm{V}_{\mathrm{BR}}$ of $450 \mathrm{~V}$, while TGDFP device with LDFP of $1.0 \mu \mathrm{m}$ results in the highest value of $500 \mathrm{~V}$ at a low leakage current below $1 \mathrm{~mA} / \mathrm{mm}$. Beyond the LDFP of $1.0 \mu \mathrm{m}, \mathrm{V}_{\mathrm{BR}}$ degrades as the distance between DFP and the gate-electrode FP (GFP) becomes narrower, adversely affecting the electric field lines distribution. In addition, a systematic comparison between TG and TGDFP devices has been analyzed and summarized in Table I. It is revealed that DFP has significant impact on $V_{B R}$ without deterioration of any other DC characteristics.

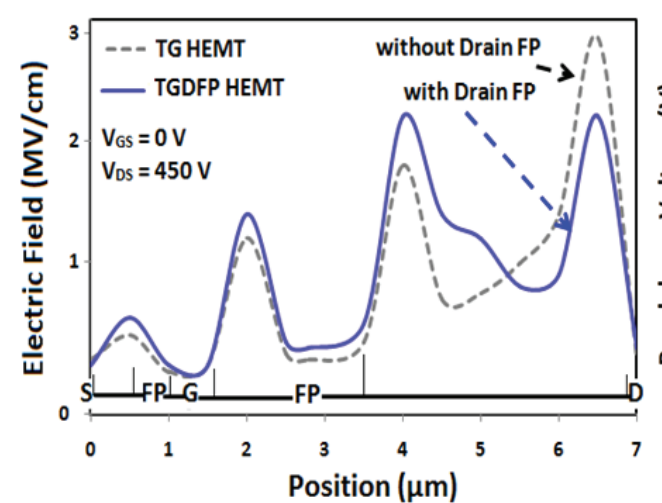

(a)

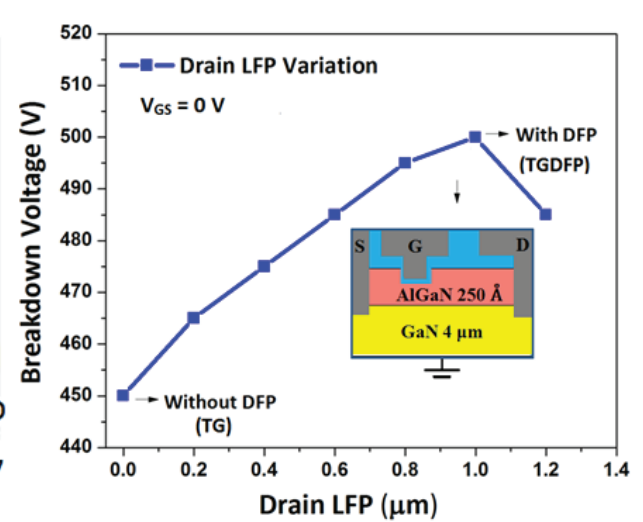

(b) (c) IEICE 2014

DOI: $10.1587 /$ elex.11.20140163 Received February 25, 2014 Accepted February 28, 2014 Publicized March 14, 2014 Copyedited March 25, 2014 
Table I. Summary of the T-gate GaN HEMT with and without DFP.

\begin{tabular}{|l|c|c|}
\hline \multicolumn{1}{|c|}{ Device Characteristics } & TG & TGDFP \\
\hline Threshold Voltage $\left(\mathrm{V}_{\mathrm{DS}}=12 \mathrm{~V}\right)$ & $+1.0 \mathrm{~V}$ & $+1.0 \mathrm{~V}$ \\
\hline Transconductance $\left(\mathrm{V}_{\mathrm{DS}}=12 \mathrm{~V}\right)$ & $137 \mathrm{mS} / \mathrm{mm}$ & $140 \mathrm{mS} / \mathrm{mm}$ \\
\hline On-state Output Current $\left(\mathrm{V}_{\mathrm{GS}}=5 \mathrm{~V}, \mathrm{~V}_{\mathrm{DS}}=30 \mathrm{~V}\right)$ & $538 \mathrm{~mA} / \mathrm{mm}$ & $540 \mathrm{~mA} / \mathrm{mm}$ \\
\hline Off-state Breakdown Voltage $\left(\mathrm{V}_{\mathrm{GS}}=0 \mathrm{~V}\right)$ & $450 \mathrm{~V}$ & $500 \mathrm{~V}$ \\
\hline Current Gain Cutoff-Frequency $\left(\mathrm{V}_{\mathrm{GS}}=3 \mathrm{~V}, \mathrm{~V}_{\mathrm{DS}}=12 \mathrm{~V}\right)$ & $3.4 \mathrm{GHz}$ & $3 \mathrm{GHz}$ \\
\hline
\end{tabular}

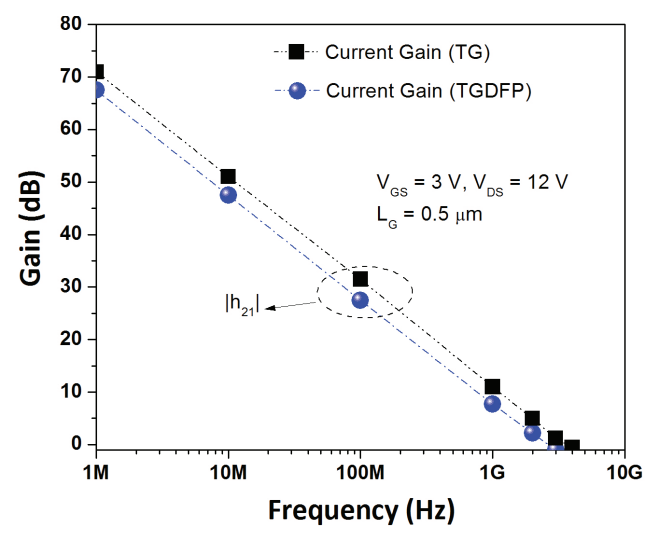

Fig. 6. Small-Signal characteristics of the recessed TG and TGDFP HEMTs.

\section{RF characteristics}

Small-signal analysis of both TG and TGDFP devices has been calculated by the TCAD simulator at a steady state operating point $\left(\mathrm{V}_{\mathrm{GS}}=3, \mathrm{~V}_{\mathrm{DS}}=\right.$ $12 \mathrm{~V}$ ) [9], with $\mathrm{L}_{\mathrm{G}}=0.5 \mu \mathrm{m}, \mathrm{t}_{\mathrm{RA}}=5 \mathrm{~nm}, \mathrm{~L}_{\mathrm{SG}}=0.8 \mu \mathrm{m}, \mathrm{L}_{\mathrm{GD}}=5.3 \mu \mathrm{m}$, $\mathrm{LDFP}=0.0 \mu \mathrm{m}(\mathrm{TG})$ and LDFP $=1.0 \mu \mathrm{m}(\mathrm{TGDFP})$. Fig. 6 shows that current gain cutoff-frequency $\left(f_{\mathrm{T}}\right)$ of $3.4 \mathrm{GHz}$ and $3 \mathrm{GHz}$ is observed for TG and TGDFP HEMTs, respectively. This revealed that DFP affects the $f_{\mathrm{T}}$ by $10 \%$, hence DFP engineering needs to be considered in the optimization of the device performance. Table I summarizes the DC and RF results of the T-gate GaN HEMT with parameters of $\mathrm{t}_{\mathrm{RA}}=5 \mathrm{~nm}, \mathrm{~L}_{\mathrm{SG}}=0.8 \mu \mathrm{m}$, $\mathrm{L}_{\mathrm{GD}}=5.3 \mu \mathrm{m}$, and $\mathrm{LDFP}=0.0 \mu \mathrm{m}(\mathrm{TG})$ or $\mathrm{LDFP}=1.0 \mu \mathrm{m}(\mathrm{TGDFP})$.

\section{Conclusion}

Recessed TGDFP GaN HEMT has been proposed by incorporating all the necessary features like enhancement-mode operation, high breakdown voltage, and high output current. DC results indicated that TGDFP HEMT achieved threshold voltage of $+1 \mathrm{~V}$, transconductance of $140 \mathrm{mS} / \mathrm{mm}$, high breakdown voltage of $500 \mathrm{~V}$, and maximum drain current of $540 \mathrm{~mA} / \mathrm{mm}$. Additionally, RF analysis revealed that this device can operate in the gigahertz frequencies. It is concluded that the lateral compact size TGDFP E-HEMT can be effectively used not only for power electronic applications like automobiles (HEV/EV) and power supplies, but also for RF sector like wireless (satellite and radar) communications. 


\section{Acknowledgments}

This work was supported by the Industrial Strategic technology development program (contract number 10038766) funded by the Ministry of Knowledge Economy (MKE, Korea) through ETRI (Electronics and Telecommunications Research Institute).

(c) IEICE 2014

DOI: 10.1587/elex.11.20140163

Received February 25, 2014

Accepted February 28, 2014

Publicized March 14, 2014

Copyedited March 25, 2014 